Discussion Paper No. 876

\title{
APPRAISING THE UNHAPPINESS \\ DUE TO \\ THE GREAT EAST JAPAN EARTHQUAKE: \\ EVIDENCE FROM WEEKLY PANEL DATA \\ ON SUBJECTIVE WELL-BEING
}

\author{
Fumio Ohtake \\ Katsunori Yamada
}

July 2013

The Institute of Social and Economic Research

Osaka University

6-1 Mihogaoka, Ibaraki, Osaka 567-0047, Japan 


\title{
Appraising the Unhappiness due to the Great East Japan Earthquake: Evidence from Weekly Panel Data on Subjective Well-being
}

\author{
Fumio Ohtake* $\quad$ Katsunori Yamada ${ }^{\dagger}$
}

\begin{abstract}
After severe disasters, persons living not only in the directly affected areas, but also in distant areas could be seriously affected thorough images of the disaster on television and in newspapers. Hence, it can be difficult to define qualified beneficiaries for policy compensation in terms of psychological suffering. Building on the case of Great East Japan Earthquake, we appraise psychological suffering from disaster-related news through the experienced utility approach. We take advantage of the serendipitous timing of our original nationwide weekly panel survey that became a timely investigation of subjective well-being in the immediate aftermath of the earthquake. Although a pale was cast over the whole society, we found that there was a robust and large geographical heterogeneity between the disaster area and non-disaster areas in mental costs. This finding may capture the focusing effect, suggesting that resources for compensating mental suffering should be concentrated on persons living in the disaster area.
\end{abstract}

Keywords: Great East Japan Earthquake, subjective well-being, experienced utility approach, focusing effect, high frequency panel data

JEL classifications: I31、H56、D61

\footnotetext{
*Institute of Social and Economic Research, Osaka University, 6-1 Mihogaoka, Ibaraki 567-0047, Japan.

$\dagger$ Corresponding author: Institute of Social and Economic Research, Osaka University and MOVE, Universitat Autonoma de Barcelona. Parmanent Address: 6-1 Mihogaoka, Ibaraki 567-0047, Japan. Tel/Fax: +81-6-6879-8566. Email: kyamada@iser.osaka-u.ac.jp
} 


\section{Introduction}

The Great East Japan Earthquake on March 11, 2011, was one of the largest earthquakes in record history and resulted in enormous physical destruction (US Geological Survey, 2011; National Police Agency of Japan 2012). Mimura (2011) and Higuchi et al. (2012) showed that the physical losses from the disaster are estimated to be around 17 trillion yen in total. Obviously, the losses from the disaster do not just include the economic costs of physical capital and the market structures which were analyzed by Ando and Kimura (2012), but also about the impacts on human beings including disease (Aoki 2012), mental trauma (Takeda 2011) and changes in risk perception (Goodwin et al. 2012). For the differential aspects of human loss, there is a widely acknowledged demand among various fields of scientists for a single index that provides a comprehensive picture of the human impact of disasters. A natural candidate for such an index is monetary evaluation of the loss in the sense of overall well-being. This is because, as Dolan and Metcalfe (2012) and Frey and Stutzer (2012) suggested, the sense of overall well-being summarizes the status of human lives and the ultimate goal of governments is to enhance the welfare of citizens.

In this paper, we take advantage of the serendipitous timing of our original nationwide weekly panel survey in the immediate aftermath of the Great East Japan Earthquake, and apply the experienced utility approach proposed by Kahneman et al. (1997) and Kahneman and Sugden (2005) to test for correlations between individuals' happiness levels and other covariates such as income levels and earthquake damage information. We then compare the magnitude of the income coefficient with that for earthquake damage to quantify the monetary value of the non- priced, psychological value of the disaster. Kahneman et al. (1997) and Kahneman and Sugden (2005) proposed the use of happiness scores to evaluate non-priced goods and bads; in this way, researchers can avoid biased estimators that inevitably result from other methods of valuing non-priced events such as the decision utility approach of choice experiments (Train et al. 1987; McFadden and Train 1996; Navrud et al. 2012). Previous studies that evaluated nonpriced goods through the experienced utility approach include Dolan et al. (2009), Welsch (2009), and Ambrey and Fleming (2011). There are also studies that evaluated non-priced bads by van Praag and Baarsma (2005), Frey et al. (2009), Oswald and Powdthavee (2008a), Dolan and Peasgood (2008), and Berger (2010).

Our data collected at the immediate aftermath of the disaster is of great value, because, as Oswald and Powdthavee (2008b) and Frijters et al. (2011) showed, it is well known that subjective well-being tends to be affected fairly soon after negative experiences, and later 
returns to previous stationary levels. Kimball et al. (2006) reported that after Hurricane Katrina, the happiness levels of Americans went back to the previous levels in three months at the longest.

While the serious psychological consequences after natural disasters are well known, evidence of monetary evaluation of psychological suffering after major disasters has been scarce. For example, in the case of a well-known disaster of Hurricane Katrina, as far as we know, there have been no studies that provide monetary estimates of psychological suffering, and only a few studies such as Kimball et al. (2006), Rateau (2009), Rhodes (2010), and LaJoie et al. (2010) have addressed well-being after the disaster. Luechinger and Raschky (2009) and Kountouris and Remoundou (2011) are the scarce examples of monetary evaluations of psychological suffering from natural disasters through the experienced utility approach. These works, however, were not based on an acute and unprecedented single event as in the case of our study. In fact, a unique feature of psychological suffering after unprecedented natural disasters is that not only directly affected persons but also people living in distant areas could be seriously affected by the disaster through images on television and in newspapers, as was shown by Metcalfe et al. (2011) in the case the September 11th terrorist attacks, a nonnatural but tremendous disaster. For policymakers this creates an allocation problem because it is difficult to define qualified recipients of compensation when a pale is cast over the whole society. The paucity of realtime monitoring of psychosocial status after major disasters and the lack of accumulated statistical evidence explain the implementation of policies on this issue have been lacking.

Our main findings are as follows. First, using news reports in the media as a proxy for the seriousness and pervasiveness of earthquake damage, we found that the mental costs of the disaster were non-negligible when compared with the total physical capital damage. Second, there is a large geographical heterogeneity in the mental costs of the disaster: people outside the disaster area were not affected by the earthquake in terms of happiness, whereas victims in Sendai City (located in the disaster zone) were affected in terms of happiness. We estimated that the total mental costs in Sendai City in the damaged area were around 30 billion euros, which is greater than the total physical damages externally reported in the city (around 17 billion euros). Hence, we suggest that policymakers devote serious attention to the mental costs of disasters, in addition to the recovery costs of physical capital, and that the resource should be concentrated on direct victims, even when the whole society was in gloom after the disaster. This information will be a help when establishing compensation schemes with greater allocation efficiency. 
Third, cherry blossom viewing (hanami), a traditional Japanese public activity in the springtime, significantly increased happiness in the Japanese people outside of the disaster area. The estimated monetary value of comfort from nature after the disaster appears significant, but again, there is a large geographical heterogeneity: when a Japanese citizen outside of Sendai City enjoys cherry blossom viewing at full bloom, the increase in happiness is equal to three times the average monthly income of a 35-year-old male worker. On the other hand, the happiness of people living in Sendai City was not increased by cherry blossom viewing in the gloom. These findings suggest that Japanese society as a whole was not mired in unhappiness after the disaster. This finding might be capturing the focusing effect (Kahneman et al. 2006; Dolan and Kahneman 2008) as illustrated by Schkade and Kahneman (1998) in the following maxim: "Nothing in life is quite as important as you think it is while you are thinking about it."

The remainder of the paper is organized as follows. In Section 2 we explain the details of our original Internet-based survey and data from external sources. The questionnaire and data construction for empirical analyses are also explained in the section. Section 3 outlines the estimation method and presents the results. Section 4 discusses implications of the results and concludes the paper.

\section{Data}

\section{$2.1 \quad$ Original survey}

This study analyzed original panel data collected through an Internet-based survey, which started around 10 days after the Great East Japan Earthquake. The weekly surveys commenced on March 22, 2011, and targeted persons residing in six cities: Fukuoka, Osaka, Nagoya, Niigata, Tokyo, and Sendai. The collected data consist of five 1-week panel surveys. These cities were chosen because they are major cities from each region of Japan, are spread across the country, and are geographically independent of each other. Respondents were randomly selected from among the registered users of My Voice Communications, Inc., a subcontracted research company, on the basis of their place of residence and regional information. As there were only a small number of respondents from each city, a stratified random sample was not used to match the distribution of individual characteristic variables such as age and educational level in each city. Overall, 2,816 respondents completed the first survey and 1,766 respondents completed all 5 surveys. Therefore, the average retention rate of respondents from one survey to the next was around $90 \%$, which 
is a fairly good rate for this type of survey. Among the 1,766 respondents who completed all 5 surveys, their places of residence were the following: 281 from Fukuoka, 304 from Osaka, 291 from Nagoya, 273 from Niigata, 318 from Tokyo's 23 wards, and 299 from Sendai. Because of inconsistent responses and/or relocations during the study period, some respondents were eliminated. In the end, balanced panel data were obtained from 1,674 respondents. Table 1 shows the means of the first-wave variables for our study sample.

Each survey wave was continued until the number of respondents reached the targeted amount. The second, third, fourth, and fifth waves were launched on March 28, April 4, April 11, and April 18, respectively. In most cases, 95\% of all data were collected within the first 2 days. Respondents who completed a survey received monetary compensation, and those who completed all 5 surveys received a bonus at the end.

A brief, yet detailed summary of the questionnaire is as follows. This study was conducted using a "veil of ignorance" approach where the respondents were unaware of the real intention of the study. This scheme was employed in order to reduce strategic biases and response resistance from the respondents. For example, in order to disguise the true intention of the surveys, questions on the respondents' interests in news (domestic and international) and various questions on their personalities were included. Each survey was entitled Survey on Everyday Life, making it difficult for the respondents to infer that the aim of the study was to reveal the relationships between the Great East Japan Earthquake, cherry blossoms, and their happiness. As the first survey (the first panel started on March 22) was conducted right after the Great East Japan Earthquake, the question concerning the respondents' happiness was placed fourth on the questionnaire in order to avoid biasing the respondent's sense of happiness. Figure 1 shows the evolution of the mean level of happiness across cities for the entire survey period.

One especially critical aspect from a methodological perspective was obtaining income information with sufficient variation for regression analysis, regardless of the difficulties associated with obtaining such data through 1-week panel surveys. Generally speaking, workers in Japan can be expected to be aware of their monthly, but not weekly, income. With this in mind, a question on monthly household before-tax income was asked in the first wave of the survey (March) and in the third wave of the survey (April). In addition, respondents were asked the following question in every wave of the survey: "Think of your economic activities and those of every family member you live with over this past week. Was there anything that altered your expected income, such as greater than usual overtime 
work, lottery winnings, unexpected extra income, or fewer than expected work hours?" They were then asked to specify the amount of fluctuation, if any. It is believed that this information on their weekly income captures the short-term fluctuations in respondents' income. Other points to be noted are as follow. First, because the surveys were conducted between March and April, questions on cherry blossoms and cherry blossom viewing were asked. The respondents were first asked whether they had taken seen cherry blossom that year (behavioral report). Those who had seen cherry blossoms were asked about their thoughts on the beauty of cherry blossoms (introspective report). For readers' reference, we provide a complete list of questions in the Appendix below for the first-wave survey commenced on March 22, 2011.

\subsection{Data from external sources}

\subsubsection{Earthquake damage variable:}

To examine the effect that the Great East Japan Earthquake and resulting damage had on respondents' level of happiness, the percentage of front page coverage that three major newspapers (Yomiuri, Asahi, and Nikkei) devoted to earthquake-related news was measured. Changes in the percentage of front-page coverage of earthquake-related news are believed to reflect shifts in public interest in earthquake damage at that time. This study examined if the shifts in public interest actually influenced the respondents' level of happiness. To construct the variable, we measured the percentage of front page coverage that was devoted to earthquake damage-related news in the three newspapers, and took a weighted average of the shares, taking into account the proportional circulation of each newspaper. ${ }^{1}$ Such data were obtained every day beginning on March 12, 2011, the day after the earthquake, until April 21, 2011, the end of the last survey period. The weighted average share data represent a time series of the volume of information on earthquake damage in the news media captured twice a day (morning and evening

\footnotetext{
${ }^{1}$ We retain record of our measurement of news papers in a pdf format, and it is available upon requests. The record, however, is not for publication due to property rights of the news paper companies. We in fact measured the following six categories of news; (i) negative news on earthquake damages, (ii) positive news on earthquake damages, (iii) negative news on nuclear power plants, (iv) positive news on nuclear power plants, (v) negative news on electricity supply, and (vi) positive news on electricity supply while we used only information on the first category in our happiness regressions. This happened because we noticed that it was possible that positive news on earthquake damage can make readers feel unhappy when they reflected the Earthquake events reading the positive articles. Also, in the situation where nobody was certain about the consequences of nuclear power plants incidents, a positive news on nuclear power plants, such as recovery from electrical outage, can make readers feel uneasy, which will decrease, rather than increase, the happiness of subjects. Given this observation and still on-going mixed discussions on the issue of nuclear power plants, we decided not to exploit news information related to them.
} 
papers), and serves as a proxy for a time series of negative feelings and mood in Japan after the natural disaster. The line with round dots in Figure 2 indicates the raw data. On March 11, 2011, earthquake-related news was placed on the ad column in addition to regular front-page news area, so the percentage exceeded $100 \%$ for that day. The second spike seen in the series resulted from a large aftershock quake on April 7, 2011, that had a seismic intensity of 6-upper in Sendai. In our Internet survey, information on the date and time of the response was recorded for each answer, which allowed us to match the amount of disaster-related news coverage from external information sources with each observation in our survey. We also had to keep in mind that information from newspaper came in with delay, while the subjects participating in the Internet survey tended to have access to, and be influenced by, real-time information on the Internet. Thus, when we plug in the created newspaper coverage information into the happiness equations, we applied the following rule. If a respondent answered the survey between midnight and 3:00 A.M., events occurring during that time that might influence their responses will usually be reported in that day's morning newspaper; if a respondent answered a survey between 3:00 A.M. and 2:00 P.M., events occurring during that time will be reported in that day's evening newspaper; and if a respondent answered a survey after 2:00 P.M. and before midnight, events occurring at that time will likely be reported in the following day's morning newspaper. Following these criteria, the appropriate newspaper coverage information was chosen for each respondent on the basis of the time that they completed the survey. If one assumes that people have no memory of past events and that past news does not affect current happiness at all, we could simply plug in the newspaper coverage information into the happiness equations directly. However, for many reasons we believe that past news information affects current happiness (Clark et al. 2001; Lucas et al. 2004; Clark et al. 2008). We therefore assume an accumulation process for the amount of news information using the "perpetual inventory method." The accumulation process is expressed in the equation:

$$
\operatorname{Information}(t)=(1-\delta) * \operatorname{Information}(t-1)+\operatorname{news}(t) \text {, }
$$

where $\delta$ measures how soon information loses its influence on happiness. We compared results using various $\delta$ values to see which model best explains the movement of happiness in the happiness regression shown below. Using Akaike's information criterion, we decided upon a $\delta$ value of 0.3 , meaning that a piece of information loses its impact on happiness after 4 days $\left((0.7 * 0.7)^{4}=0.0576\right)$. The line with square dots in Figure 2 represents the time series calculated using the perpetual inventory method. 


\subsubsection{Cherry blossoms variable:}

A variable on the level of cherry blossom bloom was created using the respondents' behavioral reports and the 2011 edition of Cherry Blossom Information issued by Weathermap Co., Ltd. ${ }^{2}$ First, a well-known site in each city for cherry blossom viewing was chosen according to the Cherry Blossom Information. Chuo Park, Osaka Castle Park, Nagoya Castle Park, Nishi Park, Chidorigabuchi, and Toyanogata were selected for Fukuoka, Osaka, Nagoya, Niigata, Tokyo's 23 Wards, and Sendai, respectively. The Cherry Blossom Information uses a 7-point scale to denote the cherry blossom status: (1) before bloom; (2) about to bloom; (3) half-bloom; (4) full bloom; (5) about to fall; (6) almost over; and (7) green leaves. Scores of 1 and 7 indicate that cherry blossoms were not suitable for viewing and therefore they were collapsed into one category. Normally, cherry blossoms can be viewed for two weeks on average. As Sendai City is the most northern city in the survey, cherry blossoms there started to bloom in the third week of the survey (around April 5), and reached full bloom at the end of the survey period (April 20th). On the other hand, cherry blossoms in the southern city of Fukuoka City were completely gone before April 15. These variations in the timing of blooming across the cities are important in separating the effects of cherry blossoms on happiness from the effects of other variables such as society's mood in general and nationwide economic conditions. Figure 3 depicts the progression of the cherry blossom "front" for the selected cities. Using the data from Cherry Blossom Information, we assigned a value of 0.2 points for regions having a bloom status of 1 or 7 ; 0.4 points for regions with a status of $2 ; 0.6$ points for regions with a status of 3; and 1 point for regions with a status of 4, 5 and 6 . Next, a dummy variable was created based on the respondents' behavioral reports of cherry blossoms viewings (Q19 in the case of the first wave survey). The responses given reflect four levels of exposure to and participation in viewing cherry blossoms: have not seen cherry blossoms, even in passing; have seen cherry blossoms in passing; have not been to view cherry blossoms; have been to view cherry blossoms. Persons who had seen cherry blossoms in passing or had been to a cherry blossom viewing were assigned a value of 1 , otherwise a value of 0 is assigned. Finally, a proxy variable for cherry blossom viewing for the regression was computed as the product of the scores of Cherry Blossom Information report and the dummy variable for cherry blossom viewing participation. Hence, the composite variable was created so that respondents who had not seen cherry blossoms were assigned a value of 0 (i.e., $0.4 * 0=0$ ), those who had seen cherry blossoms during half bloom were assigned

\footnotetext{
${ }^{2}$ Information was available at http://sakura.weathermap.jp/ (Accessed May 1, 2011)
} 
a value of $0.6(0.6 * 1=0.6)$, those who had seen cherry blossoms during full bloom were assigned a value of $1(1 * 1=1)$, and so forth.

\section{Empirical strategy and results}

As stated in Section 2, we use three primary sources of data in our analysis: happiness and income levels as captured in our original survey, information from three major newspapers on the damage caused by the earthquake, and reports on the blooming of cherry blossoms by a weather forecasting company. We included the last variable because the original purpose of the survey was to gauge the non-market value of the natural amenity of cherry blossoms. In a sharp contrast to the destructive forces of nature, it is interesting to see whether cherry blossom viewing-a traditional Japanese public activity in the springtime-provided psychological comfort to residents in the difficult post-disaster period, and furthermore, to place a value on such comfort.

Regarding featured variables for cherry blossoms and amount of earthquake news coverage, we considered their potential geographically heterogeneous effects on subjective well-being. The Great East Japan Earthquake occurred off the eastern coast of Japan's main island. We construct dummy variables that take the value 1 for respondents living in Sendai or in Tokyo (i.e., damaged areas). We capture the potential heterogeneous effects of earthquake news and cherry blossoms by adding interaction terms for these variables with the Sendai and Tokyo dummy variables.

We used ordinary least-squares (OLS) estimators to facilitate the monetary estimation of the value of cherry blossoms and earthquake damage news using the estimated coefficients. Even though the hierarchical and nonlinear nature of the dependent variable makes ordered probit or logit models methodologically preferable to OLS, we confirmed that the results for these models were basically similar to OLS when used with our data set (Luttmer 2005; Oswald and Wu 2010). As is typical for panel data sets, the Hausman test rejected the random effects model $(P<0.01)$ and we exploited the panel structure of our data set by employing a fixed effects model. ${ }^{3}$ Hence, fixed variables such as gender and region do not appear as independent variables in our main analysis. A fixed effects model specification mitigates the concern of biased estimators due to the omitted variable

\footnotetext{
${ }^{3}$ Nonetheless we also show the result from the random effects model for readers' references in Table 3. The table shows that widely observed patterns in happiness research such as females being happier than males, married people being happier than single subjects, and age affecting happiness in a U-shaped fashion are reconfirmed in our data set. These results are a validation of our original data set.
} 
problem. It is also noteworthy that from the nature of our high-frequency panel data, it is not plausible that we face another endogeneity problem of reverse causality between happiness and income level.

Generally in happiness regressions the following points should be noted. Since the dependent variable of the study, the level of happiness, is based on the respondents' introspective reports, variables that are independent of their introspective reports should be used as independent variables; objective variables or variables on respondents' behaviors should be used as independent variables. Hence, in order to avoid problems of endogeneity, our analysis in this study does not use any proxy variables that are based on introspective reports. These potentially interesting, but excluded, variables included the respondents' subjective evaluations of the cherry blossoms, and self-evaluations of stress and health status, and so forth. When we included these variables in the regression, the signs of estimated coefficients were as expected. However, the coefficients in the model using the introspective reports have an endogeneity problem. Thus, we do not show the results for this model since the estimated coefficients are subject to biases and are not appropriate for estimating the monetary value of the featured variables for cherry blossom viewing and earthquake damage news.

We excluded observations where subjects moved to other cities from the six targeted cities during the survey period. We did not have enough observations from respondents who changed jobs or marital status during the survey period to examine the effects of such changes on happiness. On the other hand, during the 5-week survey period, around $8 \%$ of subjects had a birthday, and thus we could control for the age effect in the fixed effects model specification. The number of observations for respondents who had changes in age turned out to be too few since in our main regression, the effect of age on happiness was not statistically significant (Table 2$){ }^{4}$

With these pieces of information we ran "happiness regressions" (Oswald 1997; Kahneman and Deaton 2010) to test for correlations between individuals' happiness levels and other covariates such as income level, earthquake damage, and cherry blossom viewing. We then compare the magnitude of the income coefficient with those for earthquake damage and cherry blossom viewing to quantify the monetary value of the non-priced,

\footnotetext{
${ }^{4}$ In the random effects model shown in Table 3, the effect of age was significant and U-shaped, as is typically found in happiness research.
} 
psychological value of these events. Our happiness equation looks like

$$
\begin{aligned}
\operatorname{SWB}_{j, t}= & \alpha I_{j, t}+\beta_{1} \text { news }_{t}+\beta_{2} \text { news }_{t} * \text { Tokyo }+\beta_{3} \text { news }_{t} * \text { Sendai }+\kappa_{1} S A K U R A_{t} \\
& +\kappa_{2} S A K U R A_{t} * \text { Tokyo }+\kappa_{3} S A K U R A_{t} * \text { Sendai }+\mathbf{x}_{\mathbf{j}, \mathbf{t}} \zeta+\mathbf{y}_{\mathbf{j}, \mathbf{t}} \eta+u_{j, t},
\end{aligned}
$$

where $S W B$ stands for happiness of subject $j$ at time $t, I$ is per capita income, news is the percentage of front page coverage that was devoted to earthquake damage-related news, $S A K U R A$ captures exposure to cherry blossoms, and Tokyo and Sendai are the region dummies. $\mathbf{x}_{\mathbf{j}, \mathbf{t}}$ contains age, square of age divided by 100 , and experience of job change in the survey period. In our regression we employed four variables for the time period of response as follows: (1) a five-banded variable for the time of day of the response; (2) three dummy variables depicting the day of the week; (3) whether the respondent completed the survey after the end of the work day; and (4) panel waves. We also created three variables on weather conditions at the time of the response: temperature, hourly amount of rainfall, and hourly length of sunlight. ${ }^{5}$ These variables are contained in vector $\mathbf{y}_{\mathbf{j}, \mathbf{t}}$. Finally, $u_{j, t}$ is the error term.

\subsection{Results}

The results in Table 2 show strong empirical support for the standard economics theory that individuals tend to report higher levels of happiness when they have higher levels of income $(p<0.01)$. The terms for "earthquake news" and "cherry blossoms" captured the base category effects for four cities (Fukuoka, Osaka, Nagoya, and Niigata), against which the effects in Tokyo and Sendai were measured. Somewhat surprisingly, the earthquake news for the base category did not have a significant effect $(P=0.538)$, although the effect was negative as expected. The Tokyo-specific effect of the earthquake was negative but not significant $(p=0.222)$. On the other hand, the Sendai-specific effect of the earthquake was very strong and robustly significant $(p<0.01)$. We found that the sum of the base category effect and Sendai-specific effect from the earthquake news was jointly significant $(p<0.05)$.

Using the coefficient values, we can therefore estimate the monetary value of earthquake news for people in Sendai, and calculate this value as negative 2,922,604 yen (i.e., $(-0.133385-0.4353981) \times 10,000 / 0.0015354))$ when the front pages of newspapers were completely filled with negative news. Taking into account the population of Sendai City

\footnotetext{
${ }^{5}$ Information about the weather conditions was taken from $h t t p: / / w w w . j m a . g o . j p / j m a / m e n u / r e p o r t . h t m l$.
} 
( 1 million at the time of the disaster), we estimated the city's mental costs due to the disaster to be around 3 trillion yen. Note that we do not argue for the accuracy of the value itself; rather, we suggest that the mental cost of the disaster was non-negligible when compared with the total physical capital damage of 1.7 trillion yen estimated by Development Bank of Japan (2011) for the inland area of Miyagi Prefecture where Sendai City is located. More importantly, for the other five cities, we estimate that the monetary value of psychological suffering from earthquake news was not statistically different from zero. Even though television and newspapers widely disseminated images of the natural disaster to millions of residents of these other cities in the weeks following the earthquake, those who lived a safe distance from the disaster zone were unaffected in terms of their happiness.

We found that cherry blossoms did increase the happiness of subjects in the four base cities following the earthquake (Table 2). The value of cherry blossom viewing as a nonpriced public good was found to be positive and statistically significant at the conventional level $(p<0.05)$. Using the OLS coefficients for income and cherry blossom viewing, we can estimate the monetary value of cherry blossom viewing at full bloom in the base cities as 998,031 yen (i.e., $0.1532377 \times 10,000 / 0.0015354$ ). When a Japanese citizen living in undamaged areas enjoys cherry blossom viewing at full bloom, the increase in happiness is equivalent to three times the average monthly income of a 35-year-old male worker. We again found heterogeneous geographical effects. The interaction terms of cherry blossoms with the Tokyo and Sendai dummy variables were both negative, but not significant ( $p=0.265$ for Tokyo and $p=0.376$ for Sendai). Interestingly, we could not reject the null hypothesis that the sum of the base category effect and Tokyo-specific effect is zero $(p=0.9234)$. This means that residents of Tokyo did not receive happiness from cherry blossom viewing during the period of mourning following the disaster. The same can be said in the case of Sendai $(p=0.9051)$.

\section{Conclusion}

Data on subjective well-being collected 2-7 weeks after the Great East Japan Earthquake reveal that in a city within the disaster zone, the estimated value of psychological suffering due to news reports on the disaster was comparable with the reported physical damages in the city, whereas the value of psychological suffering in undamaged areas was not significant. We also found a similar difference in the psychological effects of cherry 
blossoms between damaged and undamaged areas. The cherry blossoms did not provide significant comfort to citizens in damaged areas but did so in undamaged areas. Hence, there are two lessons for policymakers to learn from the current study. First, the government should devote serious attention to the mental costs of disasters in addition to the recovery of physical capital. Second, resources for compensating mental suffering should be concentrated on persons living in the disaster area. This result stands in sharp contrast to prior reports that bad news in a region affects the happiness of residents of distant areas, as in the cases of Hurricane Katrina by Kimball et al. (2006) and the 9/11 Attacks by Metcalfe et al. (2011). The Chernobyl Disaster is also an unprecedented nonnatural disaster, and Berger (2010) showed that the incident did not affect the well-being of people in Germany. Berger (2010) made an important case, but he considered only the spill-over effects of the disaster event and did not provide comparative analyses between the disaster area and distant and safe places. In this paper, we suggest that even after an unprecedented natural disaster that casted a gloom over society, there was a robust and large geographical heterogeneity between the disaster area and non-disaster areas in the mental costs. Our finding reminds us of the focusing effect (Kahneman et al. 2006; Dolan and Kahneman 2008) as captured by Schkade and Kahneman (1998) in the maxim "Nothing in life is quite as important as you think it is while you are thinking about it."

Contrary to expectations, our findings suggest that, overall, Japanese society was not mired in unhappiness. Following the earthquake, various campaigns by the media and the government urged the creation of new social bonds and a focus on shared humanity. Such advocacy may have changed attitudes in Japan, as captured in this survey soon after the earthquake. Examining the accumulation of social capital in Japan following the earthquake will be an important research topic for psychologists, sociologists, and economists in coming years.

Acknowledgement This work was conducted as part of the "Human Behavior and Socioeconomic Dynamics" project of Osaka University under the Global Centers of Excellence Program funded by Japan's Ministry of Education, Culture, Sports, Science and Technology (MEXT). Yamada was partially supported by the "KAKEN (24683006)" funded by MEXT. We thank Andrew Oswald, Nattavudh Powdthavee, Makoto Saito, Etsuro Shioji, and Kunio Urakawa for their comments on a draft of this manuscript. Excellent research assistant work by Sizuru Yamagiwa is greatly appreciated. 


\section{References}

Ambrey, C. And C. Fleming, "Valuing scenic amenity using life satisfaction data," Ecological Economics 72 (2011), 106-115.

Ando, M. And F. KimurA, "How did the Japanese Exports Respond to Two Crises in the International Production Networks? The Global Financial Crisis and the Great East Japan Earthquake," ASIAN ECONOMIC JOURNAL 26 (2012), 261-287.

Aoki, T., "The Great East Japan Earthquake Disaster and cardiovascular diseases," EUROPEAN HEART JOURNAL 33 (2012), 2796-2803.

Berger, E., "The Chernobyl Disaster, Concern about the Environment, and Life Satisfaction," Kyklos 63 (2010), 1-8.

Clark, A., E. Diener, Y. Georgellis and R. Lucas, "Lags And Leads in Life Satisfaction: a Test of the Baseline Hypothesis," Economic Journal 118 (2008), F222F243.

Clark, A., Y. Georgellis and P. Sanfey, "Scarring: The Psychological Impact of Past Unemployment," Economica 68 (2001), 221-241.

DevelopmentBankofJapan, "Estimate for damage of physical capital due to the Great East Japan Earthquake (in Japanese)," http://www.dbj.jp/ja/topics/dbj_news/2011/html/0000006633.html (Accessed 2012 June 1) (2011).

Dolan, P. And D. Kahneman, "Interpretations of utility and their implications for the valuation of health," Economic Journal 118 (January 2008), 215-234.

Dolan, P., H. Lee, D. King And R. Metcalfe, "Valuing Health Directly," British Medical Journal 339 (July 2009), 371-373.

Dolan, P. And R. Metcalfe, "Measuring Subjective Wellbeing: Recommendations on Measures for use by National Governments," JOURNAL OF SOCIAL POLICY 41 (2012), 409-427.

Dolan, P. And T. Peasgood, "Measuring Well-being for Public Policy: Preferences or Experiences?," Journal of Legal Studies 37 (2008), S5-S31. 
Frey, B., S. Luechinger And A. Stutzer, "The life satisfaction approach to valuing public goods: The case of terrorism," Public Choice 138 (March 2009), 317-345.

Frey, B. AND A. Stutzer, "The use of happiness research for public policy," Social Choice and Welfare 38 (2012), 659-674.

Frijters, P., D. Johnston And M. Shields, "Life Satisfaction Dynamics with Quarterly Life Event Data," Scandinavian Journal of Economics 113 (2011), 190-211.

Goodwin, R., M. Takahashi, S. Sun and S. Gaines, "Modeling Psychological Responses to the Great East Japan Earthquake and Nuclear Incident," PLoS ONE 7 (2012), 1-9.

Higuchi, Y., T. Inui, S. Sugiyama, K. Wakabayashi, N. Kuga, T. Hosoi, K. Ikemoto, I. Takabe, Y. Uematsu and T. ARimitsu, "Aftermath of the 3.11 Disaster: An Analytical Evaluation Using Official Statistics (in Japanese)," Economic and Social Research Institute Discussion Papers 286 (April 2012), 1-36.

Kahneman, D. And A. Deaton, "High income improves evaluation of life but not emotional well-being," Proceedings of the National Academy of Sciences 107 (September 2010), 16489-16493.

Kahneman, D., A. B. Krueger, D. Schkade, N. Schwarz and A. A. Stone, "Focusing Illusion Would You Be Happier If You Were Richer?," Science 312 (2006), 1908-1910.

Kahneman, D. And R. Sugden, "Experienced utility as a standard of policy evaluation," Environmental and Resource Economics 32 (2005), 161-181.

Kahneman, D., P. Wakker And R. Sarin, "Back to Bentham? Explorations of Experienced Utility," Quarterly Journal of Economics 112 (1997), 375-405.

Kimball, M., H. Levy, F. Ohtake and Y. Tsutsui, "Unhappiness after Hurricane Katrina," National Bureau of Economic Research, Working Papers 12062 (March 2006).

Kountouris, Y. And K. Remoundou, "Valuing the Welfare Cost of Forest Fires: a Life Satisfaction Approach," KYKLOS 64 (2011), 556-578.

LaJoie, A., G. Sprang And W. McKinney, "Long-term effects of Hurricane Katrina on the psychological well-being of evacuees," DISASTERS 34 (2010), 1031-1044. 
Lucas, R., A. Clark, Y. Georgellis and E. Diener, "Unemployment Alters the Set-Point for Life Satisfaction," Psychological Science 15 (2004), 8-14.

Luechinger, S. AND P. RASChKy, "Valuing flood disasters using the life satisfaction approach," JOURNAL OF PUBLIC ECONOMICS 93 (2009), 620-633.

Luttmer, E. F. P., "Neighbors as Negatives: Relative Earnings and Well-Being," The Quarterly Journal of Economics 120 (August 2005), 963-1002.

McFadden, D. And K. Train, "Consumers' Evaluation of New Products: Learning from Self and Others," Journal of Political Economy 104 (1996), 683-703.

Metcalfe, R., N. Powdthavee and P. Dolan, "Destruction and Distress: Using a Quasi-Experiment to Show the Effects of the September 11 Attacks on Mental Wellbeing in the United Kingdom," Economic Journal 121 (2011), F81-F103.

Mimura, N., "Damage from the Great East Japan Earthquake and Tsunami - A quick report," MITIGATION AND ADAPTATION STRATEGIES FOR GLOBAL CHANGE 16 (2011), 803-818.

NationalPoliceAgencyofJapan, "Damage situation and police countermeasures associated with the 2011 Tohoku district earthquake," Technical Report, http://www.npa.go.jp/archive/keibi/biki/higaijokyo_e.pdf (Accessed 2012 June 1) (Accessed 2012 June 1), May 2012.

Navrud, S., T. Tuan And B. Tinh, "Estimating the welfare loss to households from natural disasters in developing countries: a contingent valuation study of flooding in Vietnam," GLOBAL HEALTH ACTION 5 (2012), 1-11.

Oswald, A., "Happiness and Economic Performance," Economic Journal 107 (November 1997), 1815-1831.

Oswald, A. And N. Powdthavee, "Death, Happiness, and the Calculation of Compensatory Damages," Journal of Legal Studies 37 (2008a), S217-S251.

- "Does happiness adapt? A longitudinal study of disability with implications for economists and judges," Journal of Public Economics 92 (2008b), 1061-1077.

Oswald, A. And S. Wu, "Objective Confirmation of Subjective Measures of Human Well-Being: Evidence from the U.S.A.," Science 327 (2010), 576-579. 
Rateau, M., "Differences in Emotional Well-being of Hurricane Survivors: A Secondary Analysis of the ABC News Hurricane Katrina Anniversary Poll," ARCHIVES OF PSYCHIATRIC NURSING 23 (2009), 269-271.

Rhodes, J., "The Impact of Hurricane Katrina on the Mental and Physical Health of Low-Income Parents in New Orleans," AMERICAN JOURNAL OF ORTHOPSYCHIATRY 80 (2010), 237-247.

Schkade, D. And D. Kahneman, "Does living in California make people happy? A focusing illusion in judgments of life satisfaction," Psychological Science 9 (September 1998), 340-346.

TAKedA, M., "Mental health care and East Japan Great Earthquake," PSYCHIATRY AND CLINICAL NEUROSCIENCES 65 (2011), 207-212.

Train, K., D. McFadden and M. Ben-Akiva, "The Demand for Local Telephone Service: A Fully Discrete Model of Residential Calling Patterns and Service Choices," Rand Journal of Economics 18 (1987), 109-123.

US-Geological-Survey, "Poster of the Great Tohoku Earthquake (northeast Honshu, Japan) of March 11, 2011," Technical Report, http://earthquake.usgs.gov/earthquakes/eqarchives/poster/2011/20110311.php (Accessed 2012 June 1), 2011.

van Praag, B. M. S. and B. E. BaArsma, "Using Happiness Surveys to Value Intangibles: The Case of Airport Noise," Economic Journal 115 (January 2005), 224246.

Welsch, H., "Implications of Happiness Research for Environmental Economics," Ecological Economics 68 (September 2009), 2735-2742.

\section{Appendix}

Questionnaire from the first-wave: 
Q1: When you were a child, when did you most often do your homework assigned before a vacation? Choose the most appropriate option:

(1) At the beginning of the vacation; (2) During the first half of the vacation; (3) Evenly every day; (4) During the latter half of the vacation; (5) At the end of the vacation.

Q2: What percentage of chance of rain is high enough for you to take an umbrella with you when you go out?

Q3: How do you usually feel and behave when people are having fun?

(1) Have fun with them; (2) Try to have fun, but stay aloof; (3) Indifferent/ neutral; (4) Try to keep as much distance as possible; (5) Do not get involved and feel left alone.

Q4: In general, how happy are you now? On a scale from 0 to 10 with 10 being "very happy" and 0 being "very unhappy," how would you rate your happiness?

Q5: Are you sad now? Choose the most appropriate number:

(1) Sad; (2) Relatively sad; (3) Neutral; (4) Not really; (5) Not sad.

Q6: Q6: Are you happy now? Choose the most appropriate number:

(1) Happy; (2) Relatively happy; (3) Neutral; (4) Not really; (5) Not happy.

Q7: Are you depressed now? Choose the most appropriate number:

(1) Depressed; (2) Relatively depressed; (3) Neutral; (4) Not really; (5) Not depressed.

Q8: Think of the most important personal news or one event that happened around you recently. It can be either good or bad. How would you rate the news or the event on a scale of 0 to 10 with 10 being "the best" and 0 being "the worst"? 
Q9: What did the news or the event you chose for Q8 concern? Choose the most appropriate option from the following:

(1) Human relationships; (2) Work; (3) Family life; (4) Health/sickness/injury; (5) Education and future; (6) Financial issues; (7) Other.

Q10: Think of the most important news you have read in the newspaper or seen on TV recently. It can be either good or bad. How would you rate the news on a scale 0 to 10 with 10 being "the best" and 0 being "the worst"?

Q11: What did the news you chose for Q10 concern? Choose the most appropriate category from the following:

(1) Domestic politics; (2) Domestic economics; (3) Domestic crime; (4) Domestic natural disasters/accidents; (5) Domestic sports; (6) Domestic entertainment; (7) Domestic education and science; (8) Domestic social issues; (9) Other domestic topic; (10) International politics; (11) International economics; (12) International crime; (13) International natural disasters/ accidents; (14) International sports; (15) International entertainment; (16) International education and science; (17) International social issues; (18) Other international topic.

Q12: Q12: Did you sleep well last night?

(1) Not at all; (2) Not very much; (3) Neither yes nor no; (4) Somewhat well; (5) Very well.

Q13: Q13: How healthy are you?

(1) Not healthy; (2) Not very healthy; (3) Neither healthy nor unhealthy; (4) Relatively healthy; (5) Healthy.

Q14: Do you currently have hay fever?

(1) Yes; (2) Somewhat yes; (3) Neither yes nor no; (4) Not really; (5) No. 
Q15: Are you worried or stressed about something now?

(1) Yes; (2) Somewhat yes; (3) Neither yes nor no; (4) Not really; (5) No.

Q16: Have you worked or done household chores today (or if a student, have you had classes)? Or will you later today?

(1) Yes, I have; (2) Not yet, but I am going to; (3) I am doing so right now; (4) Only household chores; (5) Not yet and not going to either.

Q17: Think of one thing you did recently for a change or for recreation. Which one of the following was that?

(1) Sports; (2) Drinking and eating; (3) Travel; (4) Shopping; (5) Making something/doing carpentry/creating something; (6) Movie, TV, or music; (7) Other.

Q18: Answer this question if you chose answer (3) for Q17. Were the cherry blossoms blooming where you went?

(1) Cherry blossoms were in full bloom; (2) Cherry blossoms were about to be in full bloom; (3) Neither yes nor no; (4) Cherry blossoms were not about to be in full bloom; or (5) Cherry blossoms were not blooming.

Q19: Have you recently seen news on cherry blossoms or have actually viewed cherry blossoms?

(1) I have not seen cherry blossoms either in the newspaper or on TV news, nor have I seen cherry blossoms in person; (2) I have seen cherry blossoms in the newspaper and/or on TV, but have not seen them in person; (3) I have not been to view cherry blossoms, but I have seen them in passing; (4) I have been to view cherry blossoms.

Q20: Answer this question if you chose answer (2), (3), or (4) for Q19. How would you rate the cherry blossoms you saw on a scale of 0 to 10 with 10 being "very beautiful" and 0 being "not beautiful at all"? 
Q21-Q25: Questions on individual attributes: gender (Q21), age (Q22), marital status (Q23), number of family members in household (Q24), and occupation (Q25).

Q26: How much will your before-tax household income be this month? Add up the incomes of every family member you live with and round up to the nearest thousand yen. Give an approximate estimated amount from previous months.

Q27: Think of your economic activities and those of every family member you live with over this past week. Was there anything that altered your expected income, such as greater than usual overtime work, lottery winnings, unexpected extra income, or fewer than expected work hours? If there was any fluctuation, write down the difference in the expected income caused by such events from the amount you answered for Q26. Indicate an unexpected income increase with a plus sign $(+)$ and an unexpected income decrease with a minus sign (-).

Q28: Where is your current place of residence?

(1) Fukuoka City; (2) Osaka City; (3) Nagoya City; (4) Niigata City; (5) Tokyo's 23 Wards; (6) Sendai City; (7) Other (please specify). 
Figure 1: Change in Happiness by City from March 22 to April 21, 2011
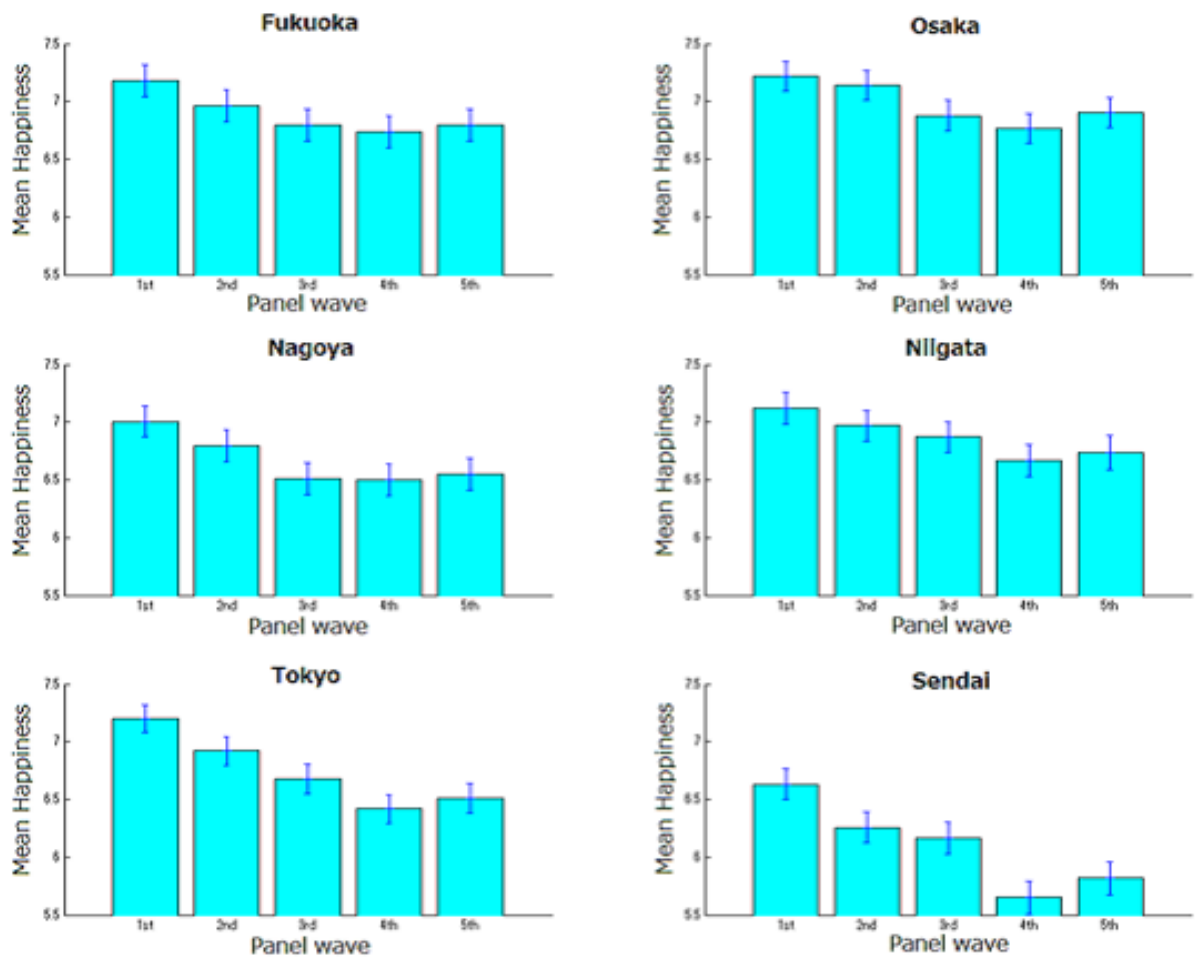

The average levels of happiness for each panel wave by city are displayed. Whisker bars show the $5 \%$ confidence intervals. 
Figure 2: Time Series of Twice-daily Information on the Amount of Earthquake-related News Coverage

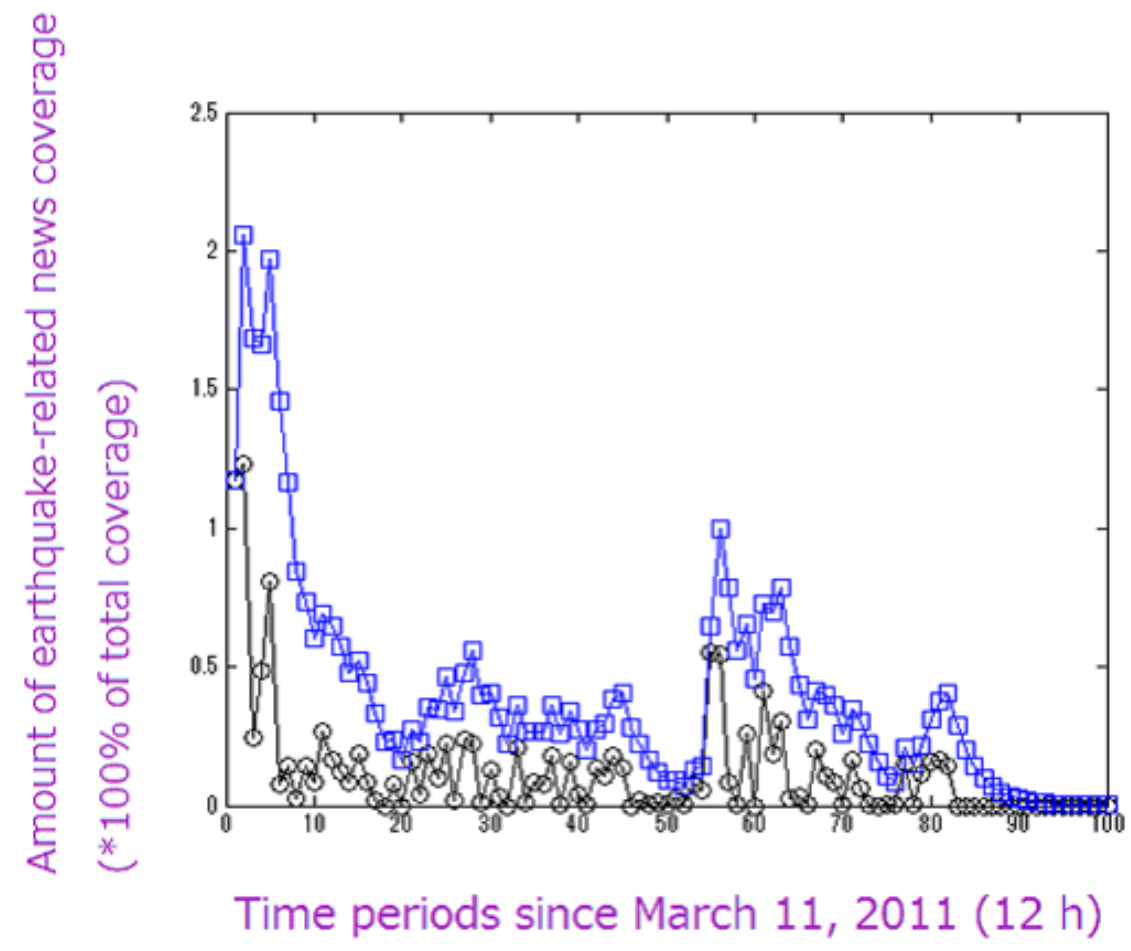

The black circle line shows raw weighted news coverage per period (half a day) for the major newspapers (Yomiuri, Asahi, and Nikkei). The blue square line shows cumulative news coverage using the perpetual inventory method $(\delta=0.3)$ 
Figure 3: Progress of Cherry Blossoms during the Survey Period
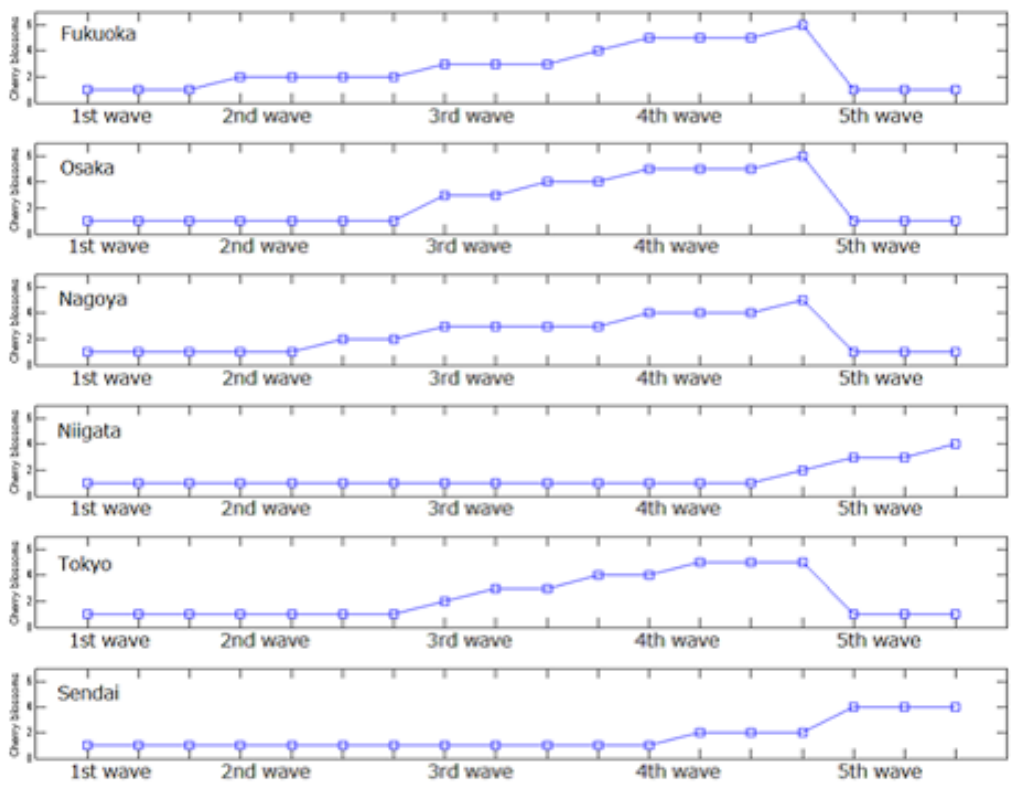

The report Cherry Blossom Information by Weathermap Co., Ltd., uses a 7-point scale: (1) before bloom; (2) about to bloom; (3) half-bloom; (4) full bloom; (5) about to fall; (6) almost over; and (7) green leaves. Scores of 1 and 7 indicate that the cherry blossoms were not suitable for viewing and therefore they were collapsed into a single category. 
Table 1: Summary Statistics for the First Wave of "Survey on Everyday Life" $(\mathrm{N}=1,674)$

\begin{tabular}{lcc}
\hline & Mean & SD \\
\hline Life happiness & 7.062 & 2.198 \\
Monthly household income (10,000 JPY) & 65.441 & 151.092 \\
Number of household & 2.854 & 1.331 \\
Monthly income per capital (10,000 JPY) & 24.354 & 48.937 \\
Female & 0.510 & 0.500 \\
Age & 41.729 & 9.923 \\
Marital status (=1 if single) & 0.386 & 0.487 \\
Fukuoka & 0.161 & 0.368 \\
Osaka & 0.173 & 0.378 \\
Nagoya & 0.163 & 0.370 \\
Niigata & 0.180 & 0.385 \\
Tokyo & 0.157 & 0.363 \\
Sendai & 0.166 & 0.372 \\
Sadness (1-5 Scale) & 2.989 & 1.221 \\
Pleasure (1-5 Scale) & 3.014 & 0.970 \\
Depression (1-5 Scale) & 2.795 & 1.199 \\
Healthy (1-5 Scale) & 3.357 & 0.986 \\
Sleep well (1-5 Scale) & 3.020 & 1.307 \\
Hay fever (1-5 Scale) & 2.578 & 1.667 \\
Stress (1-5 Scale) & 3.898 & 1.044 \\
\hline
\end{tabular}




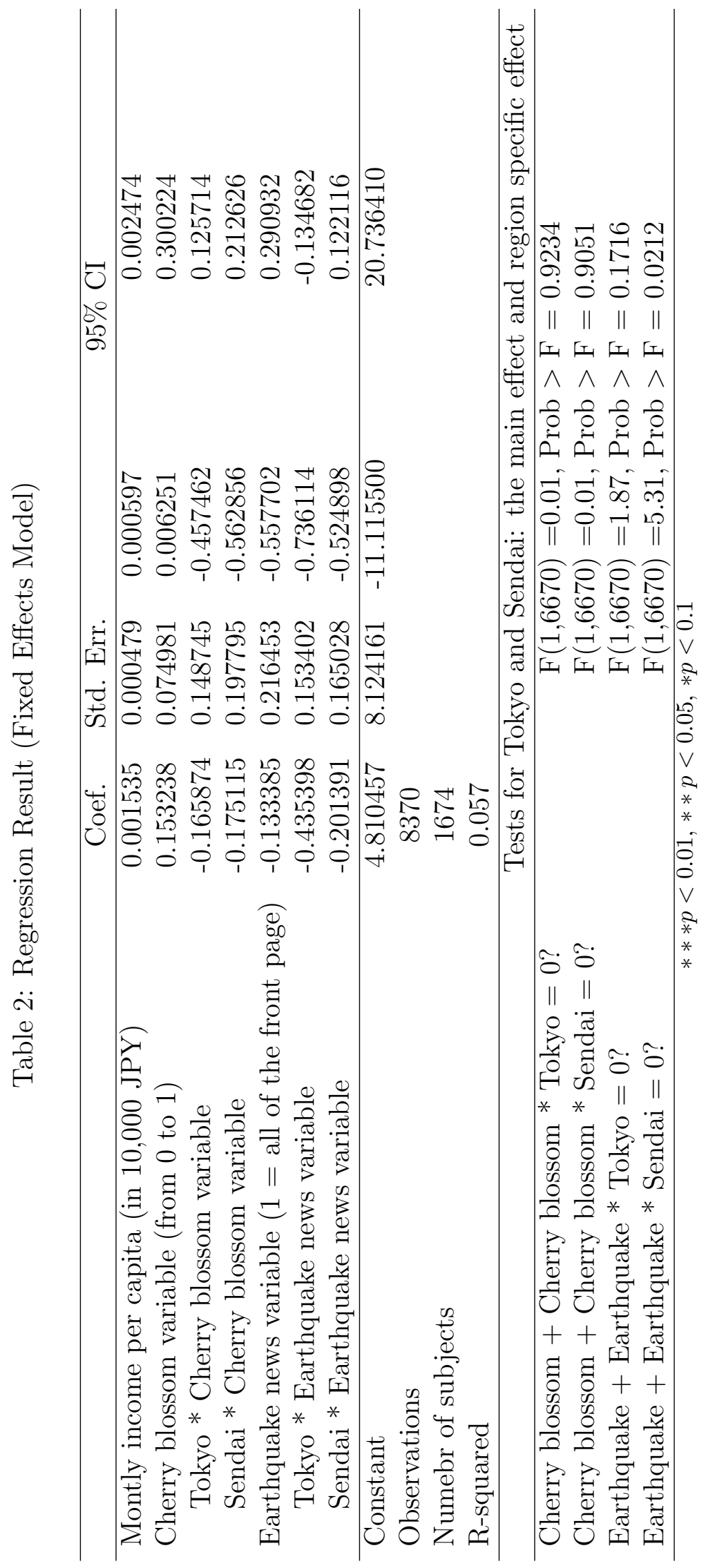


Table 3: Regression Result (Random Effects Model)

\begin{tabular}{|c|c|c|c|c|c|}
\hline & Coef. & Std. Err. & $\mathrm{Z}$ value & \multicolumn{2}{|c|}{$95 \% \mathrm{CI}$} \\
\hline Montly income per capita (in 10,000 JPY) & $0.002^{* * *}$ & 0.000 & 4.010 & 0.001 & 0.003 \\
\hline Cherry blossom variable (from 0 to 1 ) & $0.197^{* * *}$ & 0.075 & 2.640 & 0.051 & 0.343 \\
\hline Tokyo $*$ Cherry blossom variable & -0.166 & 0.148 & -1.120 & -0.456 & 0.124 \\
\hline Sendai $*$ Cherry blossom variable & -0.160 & 0.197 & -0.810 & -0.546 & 0.226 \\
\hline Earthquake news variable $(1=$ all of the front page $)$ & -0.144 & 0.216 & -0.670 & -0.568 & 0.280 \\
\hline Tokyo $*$ Earthquake news variable & $-0.416^{* * *}$ & 0.154 & -2.710 & -0.718 & -0.115 \\
\hline Sendai $*$ Earthquake news variable & -0.215 & 0.165 & -1.300 & -0.539 & 0.108 \\
\hline Age & $-0.115^{* * *}$ & 0.034 & -3.400 & -0.182 & -0.049 \\
\hline Age squared/ 100 & $0.130^{* * *}$ & 0.039 & 3.300 & 0.053 & 0.207 \\
\hline \multicolumn{6}{|l|}{ Have you worked or done household chores today? } \\
\hline Yes I have & $0.104^{* *}$ & 0.049 & 2.110 & 0.007 & 0.201 \\
\hline Not yet, but I am going to & -0.014 & 0.070 & -0.190 & -0.151 & 0.124 \\
\hline I am doing so right now & $0.153^{* * *}$ & 0.062 & 2.460 & 0.031 & 0.275 \\
\hline \multicolumn{6}{|l|}{ Only household chores (omitted category) } \\
\hline 1st wave & $0.430^{* * *}$ & 0.079 & 5.450 & 0.275 & 0.584 \\
\hline 2nd wave & $0.299 * * *$ & 0.047 & 6.330 & 0.207 & 0.392 \\
\hline 3rd wave & 0.060 & 0.054 & 1.120 & -0.045 & 0.166 \\
\hline 4th wave & -0.006 & 0.112 & -0.050 & -0.225 & 0.213 \\
\hline \multicolumn{6}{|l|}{ 5th wave (omitted category) } \\
\hline \multicolumn{6}{|l|}{ Monday (omitted category) } \\
\hline Tuesday & -0.080 & 0.127 & -0.630 & -0.330 & 0.169 \\
\hline Wednesday & -0.040 & 0.107 & -0.380 & -0.250 & 0.169 \\
\hline Thursday & 0.121 & 0.105 & 1.150 & -0.086 & 0.328 \\
\hline \multicolumn{6}{|l|}{ Time when answered the survey } \\
\hline \multicolumn{6}{|l|}{ 0:00AM to 3:59AM (omitted category) } \\
\hline 4:00AM to 8:59AM & -0.053 & 0.076 & -0.700 & -0.201 & 0.095 \\
\hline 9:00AM to $14: 59 \mathrm{PM}$ & $0.161^{*}$ & 0.089 & 1.810 & -0.014 & 0.335 \\
\hline 15:00PM to $20: 59 \mathrm{PM}$ & -0.020 & 0.071 & -0.280 & -0.159 & 0.119 \\
\hline $21: 00 \mathrm{PM}$ to $23: 59 \mathrm{PM}$ & 0.048 & 0.037 & 1.290 & -0.025 & 0.122 \\
\hline Hourly amount of rainfall & 0.014 & 0.015 & 0.890 & -0.017 & 0.044 \\
\hline Hourly sunlight & 0.000 & 0.001 & -0.150 & -0.002 & 0.002 \\
\hline Temperature & -0.007 & 0.007 & -1.020 & -0.022 & 0.007 \\
\hline Fukuoka & $0.590^{* * *}$ & 0.171 & 3.450 & 0.255 & 0.926 \\
\hline Osaka & $0.740^{* * *}$ & 0.168 & 4.410 & 0.411 & 1.068 \\
\hline Nagoya & $0.550^{* * *}$ & 0.170 & 3.240 & 0.217 & 0.883 \\
\hline Niigata & $0.364^{* * *}$ & 0.170 & 2.140 & 0.030 & 0.698 \\
\hline Tokyo & $0.560^{* * *}$ & 0.169 & 3.310 & 0.228 & 0.891 \\
\hline \multicolumn{6}{|l|}{ Sendai (omitted category) } \\
\hline Single & $-0.963^{* * *}$ & 0.093 & -10.350 & -1.145 & -0.781 \\
\hline Female & $0.948^{* * *}$ & 0.093 & 10.230 & 0.767 & 1.130 \\
\hline Job change & 0.182 & 0.165 & 1.110 & -0.141 & 0.506 \\
\hline Constant & $8.430^{* * *}$ & 0.740 & 11.390 & 6.980 & 9.881 \\
\hline Observations & 8370 & & & & \\
\hline R-squared & 0.053 & & & & \\
\hline
\end{tabular}

